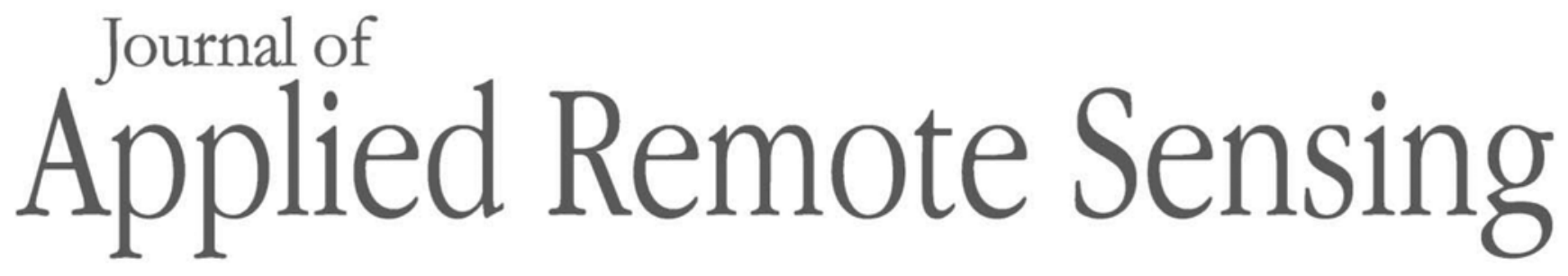

RemoteSensing.SPIEDigitalLibrary.org

\title{
Evaluation of a moderate resolution imaging spectroradiometer triangle- based algorithm for evapotranspiration estimates in subalpine regions
}

Kyle R. Knipper

Alicia M. Kinoshita

Terri S. Hogue

\section{SPIE.}




\title{
Evaluation of a moderate resolution imaging spectroradiometer triangle-based algorithm for evapotranspiration estimates in subalpine regions
}

\author{
Kyle R. Knipper, ${ }^{\mathrm{a}, *}$ Alicia M. Kinoshita, ${ }^{\mathrm{b}}$ and Terri S. Hogue ${ }^{\mathrm{a}}$ \\ ${ }^{a}$ Colorado School of Mines, Hydrologic Science and Engineering, Department of Civil and \\ Environmental Engineering, 1500 Illinois Street, Golden, Colorado 80401, United States \\ ${ }^{\mathrm{b}}$ San Diego State University, Department of Civil, Construction, and Environmental \\ Engineering, 5500 Campanile Drive, San Diego, California 92182, United States
}

\begin{abstract}
The current study evaluates the application of a moderate resolution imaging spectroradiometer (MODIS) triangle-based method to estimate evapotranspiration (ET) in subalpine environments. Topographic corrections and improved soil moisture representation are applied to a previously developed net radiation $\left(R_{\mathrm{n}}\right)$ model and triangle algorithm to develop an 8-day average ET product based solely on satellite products. We evaluate modeled $R_{\mathrm{n}}$ and MODIS ET (MOD-ET) against ground-based values at four sites in the Sierra Nevada of northern California and also present a comparison between two monthly distributed ET datasets [operational simplified surface energy balance (SSEBop) and MODIS MOD16]. Modeled daily $R_{\mathrm{n}}$ results indicate a systematic underestimation (between -83 and $-110 \mathrm{~W} / \mathrm{m}^{2}$ bias). Consequently, $R_{\mathrm{n}}$ is bias-corrected before calculating MOD-ET. MOD-ET validation shows correlations between 0.15 and 0.45 with errors between 73 and $126 \mathrm{~W} / \mathrm{m}^{2}$. MOD-ET and SSEBop ET report correlations of 0.36 and 0.20 , respectively, on average, compared to ground-based monthly ET. MOD16 underestimates monthly totals, with bias values on the range of -14 to $-144 \mathrm{~W} / \mathrm{m}^{2}$. Semiarid conditions and scale differences between the MODIS pixel and station contribute to errors with respect to observation. Overall, MOD-ET provides reasonable ET estimates and may better capture temporal dynamics in environments undergoing chronic disturbance. () The Authors. Published by SPIE under a Creative Commons Attribution 3.0 Unported License. Distribution or reproduction of this work in whole or in part requires full attribution of the original publication, including its DOI. [DOI: 10.1117/1.JRS.10.016002]
\end{abstract}

Keywords: evapotranspiration; triangle method; moderate resolution imaging spectroradiometer; semiarid; subalpine; evaporative fraction.

Paper 15444 received Jun. 16, 2015; accepted for publication Dec. 7, 2015; published online Jan. 19, 2016.

\section{Introduction}

Evapotranspiration (ET) is a key variable of study within multiple disciplines, including hydrology, meteorology, agriculture, and climate change science. ET governs the water cycling and energy transport among the biosphere, atmosphere, and hydrosphere and contributes largely to the prediction and estimation of regional-scale hydrologic processes, large-scale atmospheric circulation, and global climate change. ${ }^{1-3}$ The accurate characterization of ET flux across spatial and temporal scales is critical, especially in arid and semiarid environments where water deficiency may cause economic and political stress and constraints on sustainable development. ${ }^{4}$

ET remains one of the most challenging hydrologic components to estimate as it depends on various climatological parameters such as temperature, solar radiation, wind speed, and vapor pressure, and also physical soil properties, land cover, and heterogeneity of the surrounding environment. ${ }^{4-6}$ Conventional ground-based measurement techniques, such as pan estimates, weighing lysimeters, eddy covariance systems, and the Bowen ratio system, are well-established methods for observing energy fluxes between the land surface and atmosphere. ${ }^{7}$ However, these

*Address all correspondence to: Kyle R. Knipper, E-mail: kknipper@mines.edu 
techniques are point measurements with relatively small footprints that rarely exceed 1 to $2 \mathrm{~km} .{ }^{8,9}$ These traditional ground-based systems provide accurate estimates over constrained, homogeneous areas, but are not capable of representing ET dynamics over large heterogeneous areas. Alternatively, satellite remote sensing is recognized as a viable means to acquire largescale distributed data in a globally consistent and economically feasible manner ${ }^{3,10}$ due to its expansive global coverage, frequent estimates, and various spatial and temporal resolutions., ${ }^{3,11,12}$

A number of models with varying complexity have been developed to estimate regional ET by combining remote sensing observations with ancillary surface and atmospheric data. These models include mapping ET at high resolution with internalized calibration, ${ }^{13}$ surface energy balance algorithm for land, ${ }^{14,15}$ simplified surface energy balance (SSEB) ${ }^{16}$ and its operationally applied byproduct SSEBop, ${ }^{17}$ and temperature-vegetation indices $\left(T_{\mathrm{s}}-\mathrm{VI}\right)$ triangular and trapezoidal methods. ${ }^{18-22}$ Due to its simplicity, the $T_{\mathrm{s}}-\mathrm{VI}$ triangle method has been widely used as a practical means to provide a regional parameterization of ET. The triangle approach is based on the derivation of an evaporative fraction (EF) using primarily satellite-derived surface parameters and limited ground-based measurements. ${ }^{18-22}$

The $T_{\mathrm{s}}-\mathrm{VI}$ triangle method uses a triangular or trapezoidal domain created when $T_{\mathrm{s}}$ is plotted with VI and assumes a full range of soil moisture availability and fractional vegetation cover. ${ }^{4,23,24}$ The domain is characterized by two physical bounds: the upper dry (warm) and lower wet (cold) edges that represent limiting cases of soil moisture and EF by varying vegetation cover. ${ }^{3,4,21}$ The $T_{\mathrm{s}}-$ VI triangle relationship has been applied successfully in the study of soil moisture, land use, and drought monitoring. ${ }^{23,25-29}$ Since its introduction, the triangle method has undergone numerous modifications to derive regional ET estimates without ancillary data. ${ }^{4,6,9,20,22,30}$ Regardless of the modification, the general approach assumes that variations in surface temperature, from maxima to minima for a given vegetation index, are due to evaporative cooling effects rather than elevation variations. ${ }^{4,19-22}$ Consequently, a majority of studies have applied the triangle method over uniform topography, focusing on the effects of varying vegetation cover, spatial domain size, and climate. .,6,30,31 $^{4}$

The current study investigates the robustness of the triangle methodology for application in subalpine regions. An ET model by Kim and Hogue ${ }^{6}$ was successfully applied in southern Arizona and consists of a combination of the triangle method developed by Jiang and Islam $^{20}$ and an improved interpolation method of the distribution of day and night land surface temperature (LST) difference developed by Wang et al. ${ }^{22}$ The approach by Kim and Hogue ${ }^{6}$ is novel due to its sole use of moderate resolution imaging spectroradiometer (MODIS) remotesensing data to estimate $R_{\mathrm{n}}$, ground heat flux, and EF (through the $T_{\mathrm{s}}-$ NDVI spatial distribution). In the current study, we apply two variations to the framework outlined in Kim and Hogue. ${ }^{6}$ First, thermal inertia information from the MODIS sensor is corrected for terrain-induced angular effects through the cosine method. ${ }^{32,33}$ Second, the $T_{\mathrm{s}}-$ VI triangular domain is interpreted through a modified two-step interpolation scheme that (1) assumes nonlinearity between the Priestley-Taylor parameter and vegetation indices and (2) assumes the Priestley-Taylor parameter ranges from 0 to (slope of saturated vapor pressure + psychrometric constant) / slope of saturated vapor pressure. ${ }^{34}$ The objectives of the current work are to test the performance of the modified Kim and Hogue ${ }^{6}$ MODIS ET framework for its suitability in subalpine regions and evaluate its performance relative to common distributed ET products, the MODIS-based MOD16 (MOD16), and the operational simplified surface energy balance (SSEBop).

\section{Study Area}

The Sagehen Creek watershed is located $32 \mathrm{~km}$ north of Truckee, California on the eastern slope of the northern Sierra Nevada (Fig. 1). The aspect, elevation, and slope in the selected area range from $0 \mathrm{deg}$ to $360 \mathrm{deg}, 1870$ to $2650 \mathrm{~m}$ ( $2125 \mathrm{~m}$ on average), and 0 deg to $37 \mathrm{deg}$ ( $8.0 \mathrm{deg}$ on average), respectively (Fig. 2). Larger slopes correlate with higher elevations for all aspects, with an overall increase in slope with elevation [Fig. 2(d)]. Most of the area (77\%) is located below a 2200-m elevation, and less than 3\% of area is higher than $2500 \mathrm{~m}$ [Fig. 2(c)]. More than $93 \%$ of the area has a slope less than $15 \mathrm{deg}$, with sites located on and immediately surrounded by flat terrain (slope $<6 \mathrm{deg}$ ) [Fig. 2(a)]. The climate is characterized by dry summers with moderate 
Knipper, Kinoshita, and Hogue: Evaluation of a moderate resolution imaging spectroradiometer...

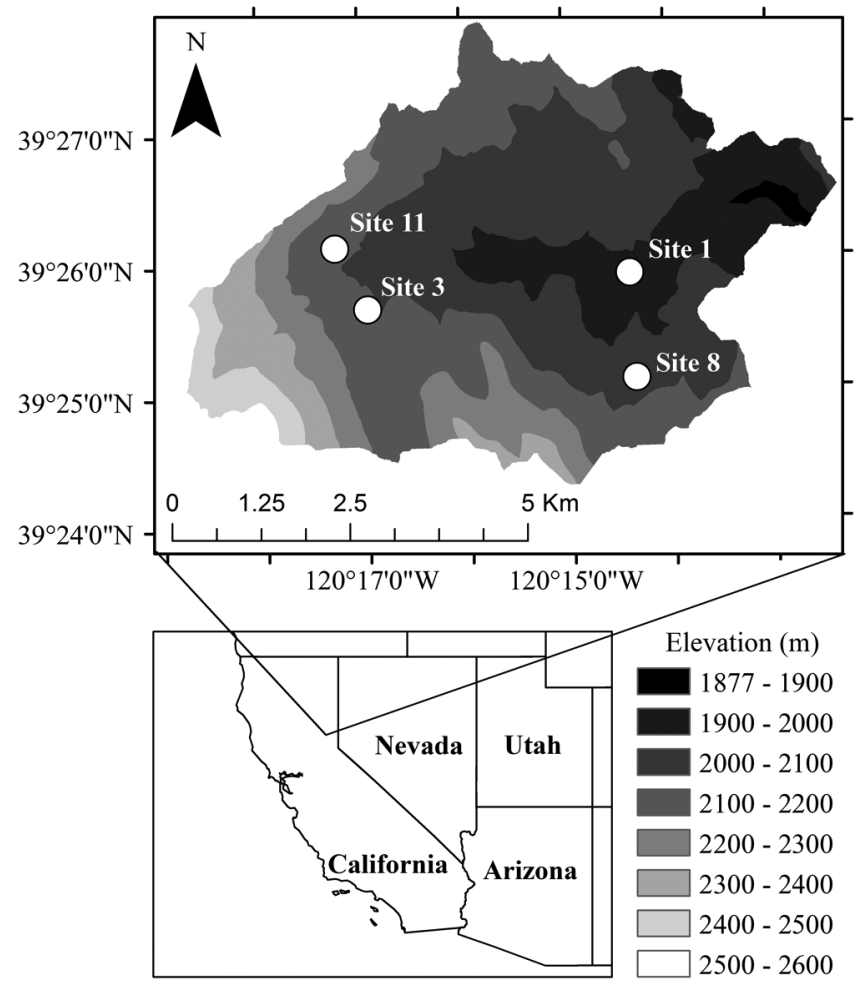

Fig. 1 Sagehen Creek watershed with study site locations 1, 3, 8, and 11 marked as circles. Elevation contours within the watershed are $100 \mathrm{~m}$.

temperatures $\left(3^{\circ} \mathrm{C}\right.$ to $\left.24^{\circ} \mathrm{C}\right)$ and wet winters with cooler temperatures $\left(-8^{\circ} \mathrm{C}\right.$ to $\left.7^{\circ} \mathrm{C}\right) .^{35}$ The most common forms of precipitation are light to moderate snow, light rain, and occasional summer thunderstorms. A majority of the precipitation occurs as snow $(\sim 85 \%)$, which accounts for 512 of the $590 \mathrm{~mm}$ of annual average total precipitation. ${ }^{35}$ Vegetation consists largely of evergreen forest (89\%), with shrub-land scattered throughout (11\%). ${ }^{36}$
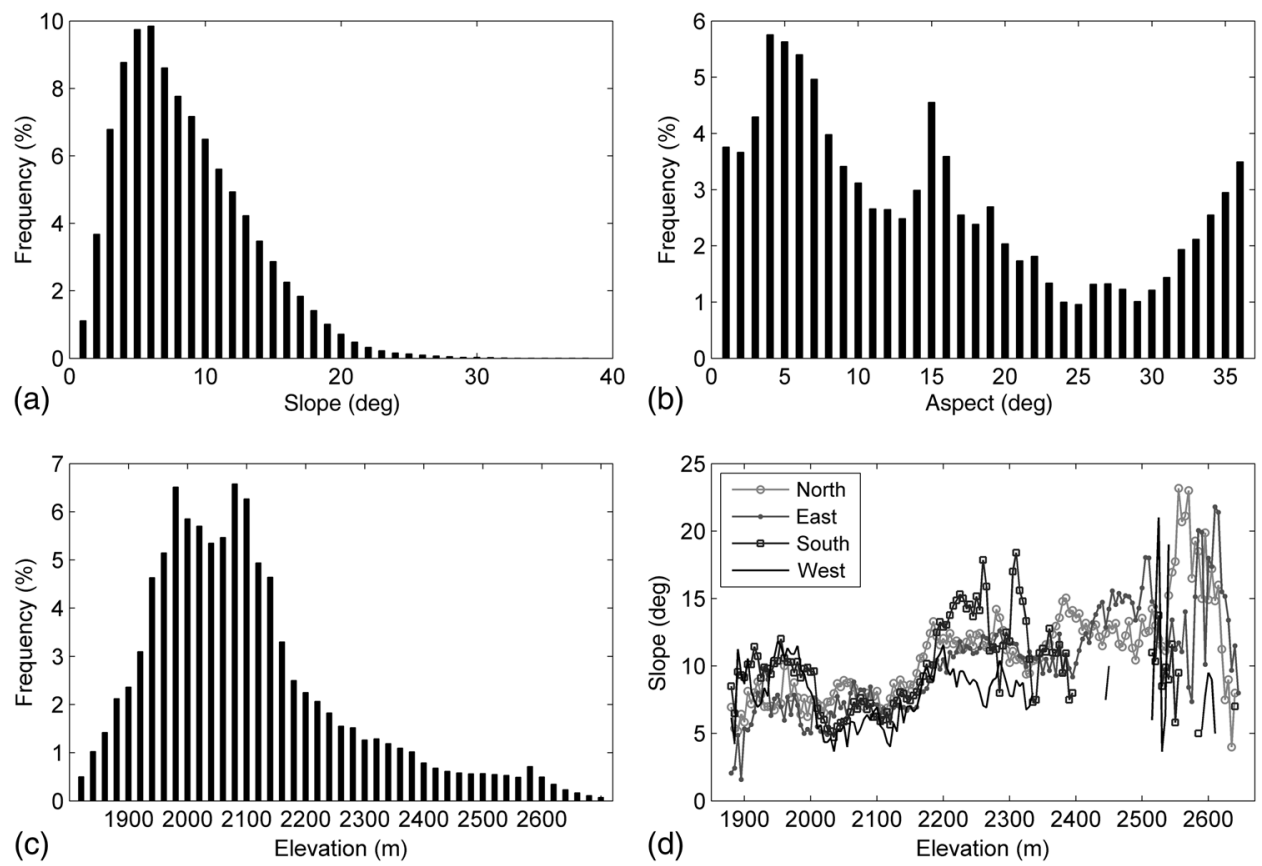

Fig. 2 Frequency of (a) slope, (b) aspect, (c) elevation, and (d) the change in slope with elevation for north, east, south, and west aspects. 


\section{Data}

\subsection{Ground-Based Evapotranspiration and Net Radiation}

The Sagehen watershed includes weather stations that provide wind speed, short wave radiation, air temperature, and relative humidity; here, we focus on sites 1, 3, 8, and 11 (Table 1). These parameters are used to mathematically estimate net radiation through parameterization schemes outlined in Brutsaert, ${ }^{37}$ and ET using the Food and Agriculture Organization (FAO) PenmanMonteith standardization calculation of reference $\operatorname{ET}\left(\mathrm{ET}_{0}\right)^{38}$ (see Appendix for details). Reported $\mathrm{ET}_{0}$ at each site is set as the standardized crop ET for short crop, with the crop coefficient designated as the grass reference value during midgrowing season. ${ }^{38}$ Reported $\mathrm{ET}_{0}$ values at each site are scaled by a soil stress coefficient $\left(K_{\mathrm{s}}\right)$ following FAO procedures ${ }^{38}$ to estimate actual ET (see Appendix for details). Additional measures are taken to confirm reliability by replacing tenuous data points (magnitudes greater than antecedent and subsequent data points) and missing data points with data points of no value. This ET is then aggregated to an 8-day daytime average ET and a total monthly ET product.

\subsection{Moderate Resolution Imaging Spectroradiometer Satellite Observations}

MODIS provides unprecedented high-quality landscape to global-scale land observations, ${ }^{39-41}$ as well as information regarding vegetation and surface energy, ${ }^{6,42}$ which are critical to the development of a remotely sensed ET model. A total of 10 variables obtained from MODIS atmospheric and land surface products are used in the MODIS ET (MOD-ET) model by Kim and Hogue ${ }^{6}$ and utilized in this study (Table 2). A combination of these variables is used to estimate $R_{\mathrm{n}}$, ground-heat flux, and EF for the development of an 8-day and monthly ET product.

All MODIS products are acquired from the NASA Reverb ECHO site ${ }^{43}$ in the standard hierarchical data format between June and October of 2010 to 2014. Eight-day composite (MYD11A2) LST products have $1 \mathrm{~km}$ spatial resolution, which include daytime and nighttime products used to calculate the difference between daytime and nighttime LST. Air temperature $\left(T_{\mathrm{a}}\right)$ is back-calculated using an interpolated ratio between air temperature from MYD07 data and surface temperature from MYD06 based on Kim and Hogue. ${ }^{6}$ Actual (blue-sky) albedo (MCD43B3) is estimated using a solar zenith angle equal to solar noon and an optical depth of 0.2 based on a known black-and-white sky albedo. ${ }^{6}$ Due to the optimization of enhanced vegetation index (EVI) in improving the vegetation signal and reducing soil background influence, ${ }^{40}$ we substitute EVI in the algorithm in place of normalized difference vegetation index (NDVI). EVI is obtained through both terra (MOD13Q1) and aqua (MYD13Q1) platforms. Each product provides a 16-day composite dataset with a $250-\mathrm{m}$ spatial resolution and phasing of both terra and aqua generates a combined 8-day time series of vegetation indices. The highest spatial resolution (250 m) based on MOD13Q1 and MYD13Q1 is used for the final spatial resolution of the proposed MOD-ET product. MODIS products with coarser resolution (1 to $5 \mathrm{~km}$ ) are resampled to a $250-\mathrm{m}$ resolution.

Table 1 Location, elevation, number of days, $n$, with available ET, slope, and aspect for sites 1, 3, 8 , and 11.

\begin{tabular}{lcccccc}
\hline \hline Site number & Latitude (deg) & Longitude (deg) & Elevation (m) & $\begin{array}{c}\text { Available ET }(n) \\
\text { (8-day period) }\end{array}$ & Slope (deg) & Aspect (deg) \\
\hline Site 1 & 39.431 & -120.240 & 1940 & 86 & 4.29 & 163.83 \\
Site 3 & 39.427 & -120.283 & 2130 & 48 & 4.29 & 62.58 \\
Site 8 & 38.418 & -120.239 & 2080 & 47 & 2.49 & 331.50 \\
Site 11 & 39.435 & -120.288 & 2110 & 17 & 5.38 & 143.97 \\
\hline \hline
\end{tabular}


Knipper, Kinoshita, and Hogue: Evaluation of a moderate resolution imaging spectroradiometer...

Table 2 Summary of MODIS products used in this study with relevant spatial and temporal information.

\begin{tabular}{|c|c|c|c|}
\hline Product name & Layer & Grid resolution (km) & Temporal resolution \\
\hline \multirow[t]{2}{*}{ MYD03 $^{\mathrm{a}}$} & Solar zenith angle & $1 \times 1$ & Daily (daytime) \\
\hline & Geolocation & $1 \times 1$ & Daily (daytime) \\
\hline MYD05_L2 ${ }^{\mathrm{a}}$ & Water vapor & $1 \times 1$ & Daily (daytime) \\
\hline \multirow[t]{3}{*}{ MYD06_L2 ${ }^{\mathrm{a}}$} & Cloud fraction & $5 \times 5$ & Daily (daytime) \\
\hline & Cloud optical thickness & $1 \times 1$ & Daily (daytime) \\
\hline & Surface temperature & $5 \times 5$ & Daily (daytime) \\
\hline \multirow[t]{3}{*}{ MYD07_L2 ${ }^{\mathrm{a}}$} & Total ozone & $5 \times 5$ & Daily (daytime) \\
\hline & Air temperature & $5 \times 5$ & Daily (daytime) \\
\hline & Dew-point temperature & $5 \times 5$ & Daily (daytime) \\
\hline \multirow[t]{2}{*}{ MYD11_L2 ${ }^{\mathrm{a}}$} & Emissivity & $1 \times 1$ & Daily (daytime) \\
\hline & LST & $1 \times 1$ & Daily (daytime) \\
\hline MOD13Q1 $1^{\mathrm{b}}$ & EVI & $250 \times 250$ & 16 days \\
\hline MYD13Q1 ${ }^{\mathrm{a}}$ & $\mathrm{EVI}$ & $250 \times 250$ & 16 days \\
\hline $\mathrm{MCD}_{3} \mathrm{~B}^{\mathrm{a}, \mathrm{b}}$ & Albedo & $1 \times 1$ & 8 days \\
\hline MYD11A $1^{a}$ & LST & $1 \times 1$ & Daily (daytime) \\
\hline 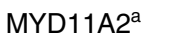 & LST & $1 \times 1$ & 8 days (daytime/nighttime) \\
\hline
\end{tabular}

aMODIS aqua satellite.

${ }^{\mathrm{b}} \mathrm{MODIS}$ terra satellite.

\section{Methodology}

The modified 8-day, $250 \mathrm{~m}$ MOD-ET product is evaluated for sites 1, 3, 8, and 11 between June and October from 2010 to 2014. First, we compare $R_{\mathrm{n}}$ estimates derived from an MODIS-based algorithm against ground-based $R_{\mathrm{n}}$ estimates. Second, we evaluate $R_{\mathrm{n}}$ bias-corrected MOD-ET to ground-based ET to estimate potential error in our interpretation of the $T_{\mathrm{s}}-\mathrm{EVI}$ domain. Following the $R_{\mathrm{n}}$ bias-corrected MOD-ET analysis, we compare MOD-ET estimates with those derived without topographic correction. Finally, we compare MOD-ET values to MOD16 and SSEBop between June and October from 2010 to 2013.

\subsection{Moderate Resolution Imaging Spectroradiometer-Based Triangle Evapotranspiration Algorithm}

\subsubsection{Estimation of available radiant energy $\left(R_{n}-G\right)$}

A satellite-based (MODIS) stand-alone methodology, initially developed by Kim and Hogue, ${ }^{44}$ is utilized for the estimation of $R_{\mathrm{n}}$. The methodology builds upon previous algorithms and equations to equate upward and downward short- and long-wave radiation under both clear and cloudy sky conditions. The $R_{\mathrm{n}}$ model developed in Kim and Hogue ${ }^{44}$ incorporates the Paulescu and Schlett model ${ }^{45}$ to determine instantaneous downward shortwave radiation under clear-sky conditions. However, the current study implements Eq. (5) as suggested by Bisht and Bras, ${ }^{46}$ along with a regional parameterization scheme from the Kim and Hogue ${ }^{44}$ methodology that requires no regional calibration. We also substitute the cloud product from MYD08 with the cloud product from MYD06. ${ }^{44}$ 
The upward longwave radiation for clear sky is expressed using the Stefan-Boltzmann equation

$$
\mathrm{Rl} \uparrow_{\text {clear }}=\varepsilon_{\mathrm{s}} \sigma T_{\mathrm{s}}^{4}
$$

where $\varepsilon_{\mathrm{s}}$ is the surface emissivity, $\sigma$ is the Stephan-Boltzmann constant $(5.67 \times$ $10^{-8} \mathrm{~W} \mathrm{~m}^{-2} \mathrm{~K}^{-4}$ ), and $T_{\mathrm{s}}$ is the surface temperature (K) (MYD11).

Downward longwave radiation for a clear sky is based on a parameterization scheme by Brutsaert ${ }^{47}$ and is estimated as

$$
\mathrm{R} 1 \downarrow_{\text {clear }}=\varepsilon_{\mathrm{a}} \sigma T_{\mathrm{a}}^{4},
$$

where $\varepsilon_{\mathrm{a}}$ is the air emissivity [determined by water vapor pressure (MYD05) and air temperature] and $T_{\mathrm{a}}$ is the interpolated air temperature (K) (MYD07).

Downward longwave radiation for cloudy pixels is estimated through a proposed methodology by Bisht and Bras ${ }^{46}$ and can be expressed as

$$
\mathrm{Rl} \downarrow_{\text {cloudy }}=\varepsilon_{\mathrm{a}} \sigma T_{\mathrm{a}}^{4}+\left(1-\varepsilon_{\mathrm{a}}\right) \varepsilon_{\mathrm{c}} \sigma T_{\mathrm{c}}^{4},
$$

where $T_{\mathrm{a}}$ is interpolated air temperature, $\varepsilon_{\mathrm{c}}$ is cloud emissivity (MYD11), and $T_{\mathrm{c}}$ is the cloud temperature (MYD06).

Under cloudy conditions, upward longwave radiation ${ }^{6}$ is estimated as

$$
\mathrm{R} 1 \uparrow_{\text {cloudy }}=\varepsilon_{\mathrm{S}_{\mathrm{A} 2}} \sigma T_{\mathrm{s}_{06}}^{4},
$$

where the surface temperature $\left(T_{\mathrm{s} 06}\right)$ is obtained from MYD06, and surface emissivity $\left(\varepsilon_{\mathrm{S}_{\mathrm{A} 2}}\right)$ is obtained from MYD11A2.

Estimation of downward shortwave radiation under clear sky conditions stems from Zillman $^{48}$ and modifications by Bisht and Bras. ${ }^{46}$ This parameterization scheme uses nearsurface vapor pressure $\left(e_{0}\right)$ (MYD07 and MYD05) and solar zenith angle $(\theta)$ (MYD03) to estimate downward shortwave radiation as follows:

$$
\text { Rs } \downarrow_{\text {clear }}=\frac{S_{0} \cos ^{2}(\theta)}{1.085 \cos (\theta)+e_{0}[2.7+\cos (\theta)] \times 10^{-3}+\beta},
$$

where $\mathrm{S}_{0}$ is the solar constant at the top of the atmosphere $\left(1367 \mathrm{~W} / \mathrm{m}^{2}\right)$. Niemelä et al. ${ }^{49}$ and Bisht et al..$^{50}$ have shown that a $\beta$ value of 0.1 corresponds to overestimation of downward shortwave radiation and have alternatively proposed a $\beta$ value of 0.2 , which is used in the current study.

Downward shortwave radiation under cloudy conditions is estimated as a linear combination of the fluxes from clear sky and cloudy sky ${ }^{46}$ and weighted by cloud fraction, as developed by Slingo $0^{51}$

$$
\text { Rs } \downarrow_{\text {cloudy }}=\operatorname{Rs} \downarrow_{\text {clear }}\left[(1-N)+N \mathrm{e}^{-\frac{\tau}{\cos \theta}}\right] \text {, }
$$

where $N$ is the cloud cover fraction (MYD06), $\tau$ is the cloud optical thickness (MYD06), and $\theta$ is the solar zenith angle (MYD03).

Using Eqs. (1)-(6), we estimate an instantaneous $R_{\mathrm{n}}$ under all sky conditions using Eq. (7) as proposed by Kim and Hogue 6

$$
R_{\mathrm{n}}=\left(1-A_{0}\right) \mathrm{Rs} \downarrow+\mathrm{R} 1 \downarrow-\mathrm{R} 1 \uparrow,
$$

where $A_{0}$ is surface albedo. Instantaneous net radiation estimates are then converted to daily average $R_{\mathrm{n}}$ estimates [Eq. (8)] through a sinusoidal function, which assumes $R_{\mathrm{n}}$ values become positive at sunrise and begin to decline during sunset ${ }^{44,50,52}$

$$
R_{\text {ndaily }}=R_{\mathrm{n} \mathrm{i}} \frac{2}{\pi \sin \left[\left(\frac{t_{i}-t_{\text {sunise }}}{t_{\text {sunset }}-t_{\text {sunrise }}}\right) \pi\right]},
$$


where $R_{\mathrm{ndaily}}$ and $R_{\mathrm{ni}}$ are daily and instantaneous $R_{\mathrm{n}}$, respectively, $t_{\text {sunrise }}$, and $t_{\text {sunset }}$ are sunrise and sunset times obtained from the US Naval Observatory and $t_{\mathrm{i}}$ is the satellite over-pass time.

Estimation of soil heat flux $\left(G_{0}\right)$ is achieved through a proposed methodology by Bastiaanssen, ${ }^{15}$ which utilizes a radiometric surface temperature product, surface albedo, and NDVI. Bastiaanssen ${ }^{15}$ computes soil heat flux empirically, by considering the effects of surface heating, soil moisture, and intercepted solar radiation

$$
G_{0}=R_{\mathrm{n}}\left[\frac{T_{\mathrm{TM} 6}}{A_{0}}\left(0.0038 A_{0}+0.0074 A_{0}^{2}\right)\left(1-0.98 \mathrm{EVI}^{4}\right)\right],
$$

where $T_{\mathrm{TM} 6}\left({ }^{\circ} \mathrm{C}\right)$ is the radiometric surface temperature, $A_{0}$ is the surface albedo, and EVI is the enhanced vegetation index (MOD13Q1 and MYD13Q1). In the current study, $T_{\mathrm{TM} 6}$ is estimated from MYD11, and albedo is estimated through the combined MODIS terra and aqua MCD43B3.

\subsubsection{Estimation of evaporative fraction}

EF is the ratio of latent heat flux (LE) to available radiant energy [Eq. (10)]. We utilize a modified methodology proposed by Kim and Hogue ${ }^{6}$ that employs the Wang et al. ${ }^{22}$ model to derive EF through an interpolation of the Priestley-Taylor parameter $(\alpha)$ from a day-night temperature difference $(\Delta T)$-EVI trapezoidal domain. We apply a temporal variation of $T_{\mathrm{s}}$ due to a significant bias from an MODIS LST product found in previous studies ${ }^{50,53,54} \mathrm{EF}$ is evaluated as

$$
\mathrm{EF}=\frac{\mathrm{LE}}{R_{\mathrm{n}}-G}=\alpha \frac{\Delta}{\Delta+\gamma},
$$

where LE is representative of ET $\left(\mathrm{W} / \mathrm{m}^{2}\right), R_{\mathrm{n}}$ is the net radiation $\left(\mathrm{W} / \mathrm{m}^{2}\right), G$ is the soil heat flux $\left(\mathrm{W} / \mathrm{m}^{2}\right), \gamma$ is the psychrometric constant $(\mathrm{hPa} / \mathrm{K}), \alpha$ is the Priestley-Taylor parameter accounting for aerodynamic and canopy resistances, and $\Delta$ is the slope of saturated vapor pressure at air temperature $(\mathrm{hPa} / \mathrm{K})$, which can be calculated as

$$
\Delta=\frac{26297.77}{\left(T_{\mathrm{a}}-29.65\right)^{2}} \exp \left[\frac{17.67\left(T_{\mathrm{a}}-273.15\right)}{T_{\mathrm{a}}-29.65}\right] \text {. }
$$

Due to a less than $5 \%$ difference between the use of air and surface temperatures ${ }^{22}$ and an instability of air temperature retrieval from MYD07 ${ }^{6}$, acquired surface temperatures from the MYD11 product are used to estimate $\Delta$ rather than air temperature. ${ }^{19,22,44}$ Surface temperatures are then corrected for terrain-induced angular effects through the cosine method ${ }^{32,33}$ as follows:

$$
T=\left(\frac{T_{\mathrm{s}}^{4}}{\cos \gamma}\right)^{1 / 4}
$$

where $T$ is the corrected LST, $T_{\mathrm{S}}$ is the satellite-derived LST, and $\gamma$ is the angle between the satellite-view path and the normal to the terrain element. ${ }^{33}$ For a thermal band, the angle of emitted radiance can be geometrically determined by

$$
\cos \gamma=\cos \omega \cos \delta+\sin \omega \sin \delta \cos \left(\phi_{\mathrm{s}}-\phi\right),
$$

where $\omega$ is the local slope angle, $\delta$ is the satellite zenith angle, $\varphi_{\mathrm{s}}$ is the satellite azimuth angle, and $\varphi$ is the aspect angle of the terrain element.

Prior to estimating EF, both dry and wet edges in the $\Delta T$ - EVI trapezoidal domain must be determined. In the current study, the wet edge is interpreted as a constant temperature line set as the minimum temperature difference. ${ }^{19,22}$ The warm edge of the trapezoidal space is estimated by establishing constant intervals of EVI and finding the maximum temperature difference associated with each interval. Assuming a linear decrease in temperature with increasing EVI, ${ }^{4,6,18-22}$ we develop a linear regression model based on the acquired maximum temperature differences and calculate the standard deviation. Maximum temperature differences exceeding one standard 
deviation from the linear regression model are considered outliers and omitted. The new set of maximum temperatures is used to redevelop the linear regression model to obtain the final dry edge and subsequently the associated maximum and minimum temperature difference.

The Priestley-Taylor parameter, $\alpha$ [Eq. (10)] for each pixel $(i)$ is determined using a two-step nonlinear interpolation scheme from the $T_{\mathrm{s}}$ - EVI trapezoidal domain. ${ }^{34}$ First, the value of $\alpha$ corresponding to the driest bare soil pixel (no vegetation and temperature is at a maximum) is set to $0\left(\alpha_{\min }=0\right)$. Next, the value of $\alpha$ corresponding to maximum vegetation on the wet edge (maximum amount of vegetation and temperature is at a minimum) is set to $(\Delta+\gamma / \Delta)\left[\alpha_{\max }=(\Delta+\gamma / \Delta)\right] .^{34}$ The value of $\alpha$ for pixel $(i)$ is estimated by determining $\alpha_{\min , i}$ by assuming that $\alpha_{\min , i}$ varies nonlinearly with EVI between $\alpha_{\min }$ and $\alpha_{\max }{ }^{34}$

$$
\alpha_{\min , i}=\alpha_{\max , i}\left(\frac{\mathrm{EVI}_{i}-\mathrm{EVI}_{\min }}{\mathrm{EVI}_{\max }-\mathrm{EVI}_{\min }}\right)^{2}
$$

Having established the upper and lower bounds of $\alpha$, the $\alpha_{i}$ for any pixel with an EVI and $\Delta T$ is determined by

$$
\alpha_{i}=\frac{\Delta T_{\max }-\Delta T_{i}}{\Delta T_{\max }-\Delta T_{\min }}\left(\alpha_{\max }-\alpha_{\min }\right)+\alpha_{\min }
$$

Finally, substituting $\alpha_{i}$ from Eq. (15) into Eq. (10), we estimate EF for any pixel within the boundary of the triangular domain as

$$
\mathrm{EF}=\frac{\Delta}{\Delta+\gamma}\left[\frac{\Delta T_{\max }-\Delta T_{i}}{\Delta T_{\max }-\Delta T_{\min }}\left(\alpha_{\max }-\alpha_{\min }\right)+\alpha_{\min }\right],
$$

where $\Delta T_{\max }$ and $\Delta T_{\min }$ are the corresponding maximum and minimum surface temperature differences (8-day composite) at the dry and wet edges, respectively, for a given EVI (8-day composite). Lastly, an 8-day ET product is derived using Eq. (17), estimated $R_{n}$ [Eq. (8)], estimated soil heat flux $\left(G_{0}\right)$ [Eq. (9)], and EF [Eq. (16)] assuming a constant EF throughout a day ${ }^{55}$

$$
\mathrm{ET}=\mathrm{EF}\left(R_{\mathrm{n}}-G\right)
$$

\subsection{Operational Evapotranspiration Products}

Modeled ET estimates are compared against ground-based ET to evaluate the performance of the global MODIS ET datasets (MOD16A2 monthly) ${ }^{56}$ and SSEBop. ${ }^{17}$

\subsubsection{MODIS MOD16 ET (MOD16)}

Global MODIS ET datasets (MOD16A2) are obtained from the University of Montana's Numerical Terradynamic Simulation Group ${ }^{57}$ and are available at spatial resolution of $1 \mathrm{~km}$ for the entire global vegetated land surface for 8-day, monthly, and annual time intervals. The original MOD16 algorithm, ${ }^{58}$ based on the Penman-Monteith equation,${ }^{59}$ has been modified to consider both the surface energy portioning process and atmospheric drivers on ET ${ }^{58,60}$ The algorithm uses a range of MODIS products, including land cover, albedo, leaf area index, and EVI. Additionally, the algorithm requires daily meteorological data inputs for regional and global ET mapping and monitoring, which are obtained from NASA's Global Modeling and Assimilation Office. ${ }^{58,60}$ In the current study, we use $1 \mathrm{~km}$, monthly MODIS MOD16 ET datasets between June and October from 2010 to 2013.

\subsubsection{Operational simplified surface energy balance}

SSEBop is an MODIS-based ET dataset based on SSEB $^{16}$ that uses model assimilated weather datasets and MODIS thermal images to produce values for the contiguous United States at 8-day, 
monthly, and seasonal timescales. ${ }^{17}$ SSEBop introduces a new simplified parameterization to estimate an actual ET value using predefined boundary conditions that are unique to each pixel for the "hot" and "cold" reference conditions. ET is then estimated as a function of LST obtained from remotely sensed data and reference ET from global weather datasets using the SSEB approach. ${ }^{16,17}$ The original SSEB formulation is enhanced with a lapse rate correction factor, significantly improving the influence of topography on surface temperature. ${ }^{17}$

Furthermore, Senay et al. ${ }^{17}$ address both elevation and latitude effects on surface temperature using an LST/air temperature difference rather than exclusively surface temperature. Because the boundary for hot and cold reference conditions are predefined for each location and period using a simplified climatological energy balance calculation procedure, ${ }^{17}$ remotely sensed LST is the only specification required by the user to estimate ET fractions, simplifying SSEBop simulation. In the current study, we utilize the $1 \mathrm{~km}$, monthly SSEBop ET generated between June and October of 2010 to 2013. SSEBop ET data are acquired through the US geological survey geo data portal. ${ }^{61}$

\section{Results and Discussion}

\subsection{Validation of Net Radiation}

We first evaluate the MOD-ET algorithm $R_{\mathrm{n}}$ values with ground-based $R_{\mathrm{n}}$. The comparison between daily ground-based $R_{\mathrm{n}}$ and daily MOD-ET $R_{\mathrm{n}}$ has root mean square error (RMSE) ranging from 106 to $132 \mathrm{~W} / \mathrm{m}^{2}$ and correlation coefficients between 0.67 and 0.80 for all sites (Fig. 3). There is also consistent model underestimation at each site, with bias values ranging from -83 to $-110 \mathrm{~W} / \mathrm{m}^{2}$ (Fig. 3). The observed negative biases trends are consistent with Kim and Hogue, ${ }^{6}$ who report bias from -102 to $-46 \mathrm{~W} / \mathrm{m}^{2}$. Kim and Hogue ${ }^{6}$ also report RMSE between 69 and $122 \mathrm{~W} / \mathrm{m}^{2}$, with correlation coefficients ranging from 0.65 to 0.69 . Bisht and Bras $^{46}$ report RMSE values and correlations of $41 \mathrm{~W} / \mathrm{m}^{2}$ and 0.88 , respectively; while Tang et al. ${ }^{31}$ report RMSE values and correlations of 57 to $84 \mathrm{~W} / \mathrm{m}^{2}$ and 0.34 to 0.50 , respectively.
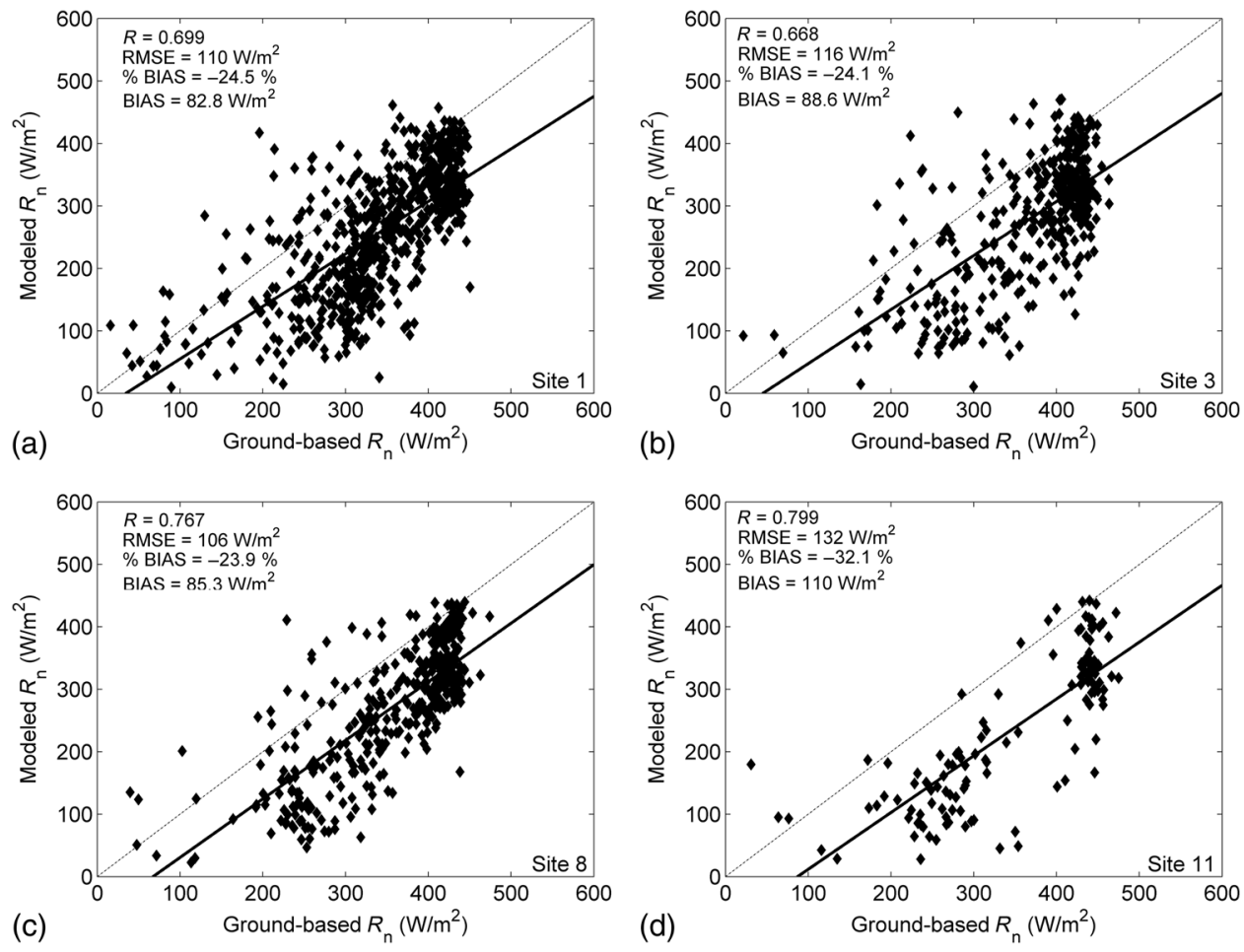

Fig. 3 Observed $R_{\mathrm{n}}$ and MODIS-derived $R_{\mathrm{n}}$ at each site (labeled in the bottom right) with correlation coefficient $(R)$, RMSE, percent bias, and bias. The dashed line represents a one-to-one correlation, while the solid line is the linear regression of the data. 
Our results show a negative bias of $\sim 25 \%$ on average between the sites. Correlations are similar or slightly better than recent studies ${ }^{6,31,46}$ and are attributed to the longer time period in the current study. Systematic underestimation of surface $R_{\mathrm{n}}$ may stem from unsatisfactory performance of the shortwave radiation scheme used in the study. ${ }^{6}$ Kim and Hogue ${ }^{6}$ report between $-17 \%$ and $-22 \%$ bias in instantaneous shortwave radiation, with RMSE errors as high as $226 \mathrm{~W} / \mathrm{m}^{2}$ when incorporating the shortwave radiation scheme. The current study finds similar trends (not shown) when comparing daily average observed shortwave radiation and modeled shortwave radiation, with bias values between -33 and $-36 \mathrm{~W} / \mathrm{m}^{2}$ and RMSE errors of $192 \mathrm{~W} / \mathrm{m}^{2}$ on average between the sites. Furthermore, it is important to note the significant uncertainty that may arise from the scale differences present when comparing an MODIS pixel to the in situ data. Several inputs, such as MYD06 and MYD07, are coarse (1 to $5 \mathrm{~km}$ ) and may not capture subtle terrain or canopy differences present at the tower sites, adding uncertainty and reducing accuracy. Although there is a slight increase in RMSE at all sites, the daily $R_{\mathrm{n}}$ estimates presented in this section are fairly similar to those reported in the literature, ${ }^{6,31,46}$ while having the added advantage of being available under all sky conditions and requiring no ground-based observations.

\subsection{Evaluation of Derived Evapotranspiration}

\subsubsection{MOD-ET versus ground-based observations}

Evaluation of MOD-ET against ground-based estimated ET is undertaken for all four study sites between the months of June and October for years 2010 to 2014. We derive new ET values based on bias-corrected $R_{\mathrm{n}}$ estimates. Bias-corrected ET estimates provide a thorough analysis of the derivation of EF from the $\Delta T_{\mathrm{s}}-\mathrm{EVI}$ domain as we are unable to directly compare observed EF to modeled EF. Lastly, we derive ET values without topographic correction (cosine method) to determine the sensitivity of the triangle method to variations in slope, aspect, and elevation.

Bias-corrected MOD-ET estimates at sites 1,3 , and 11 show positive bias $(67.0,88.7$, and $84.9 \mathrm{~W} / \mathrm{m}^{2}$, respectively), while site 8 reports a moderately positive bias at $15.3 \mathrm{~W} / \mathrm{m}^{2}$. RMSE errors and correlations range between 73.3 and $126.0 \mathrm{~W} / \mathrm{m}^{2}$ and 0.15 and 0.45 between all sites, respectively. Results from site 11 have relatively poor results that are attributed to the minimal, 17, 8-day periods of available data $(84.9,126$, and 0.15 for bias, RMSE, and correlation, respectively). Sites 1, 3, and 8 record 86, 48, and 478 -day periods of available data, respectively (Table 1). RMSE errors reported here (Fig. 4 and Table 3) are larger than those reported by Kim and Hogue, ${ }^{6}$ with lower correlations at all sites except site 1 (Fig. 4 and Table 3).

Similar overestimation of modeled ET is reported by Kim and Hogue ${ }^{6}$ at two sites characterized as having minimal soil moisture availability. However, the implementation of their triangle method under riparian or sufficient soil water content conditions shows improved performance. ${ }^{6}$ Prior to ET comparison, Kim and Hogue ${ }^{6}$ evaluated EF derived from the triangle method against observed EF, which demonstrate that the performance of the triangle method suffered under water-stressed conditions, leading to overestimations of EF and subsequently ET. Tang et al. ${ }^{31}$ also note significant overestimations of EF when applying an MODIS triangle-based ET method over two flux tower sites in southern Arizona. Additionally, Wang et al. $^{22}$ report that EF values remain nonuniform under low soil moisture content, regardless of the vegetation uniformity.

Kim and Hogue ${ }^{6}$ report systematically underestimated $R_{\mathrm{n}}$ values and overestimated ET from soil moisture limited sites. When comparing our originally derived MOD-ET product, which also utilizes slightly underestimated $R_{\mathrm{n}}$ values, we find much improved bias values (27.1, $41.8,25.2$, and $31.4 \mathrm{~W} / \mathrm{m}^{2}$ for sites $1,3,8$, and 11 , respectively). This is likely due to the nonlinear formulation of the $\Delta T_{\mathrm{s}}-$ EVI space used in the current study, which has been shown to produce lower EF estimates when compared to the linear formulation by improving moisture availability interpretation within the $\Delta T_{\mathrm{s}}$ - EVI domain. ${ }^{34}$ Because estimates of EF and $R_{\mathrm{n}}$ are independent from one another, we are able to bias correct $R_{\mathrm{n}}$ and relate errors in ET to the EF. As previously mentioned, $R_{\mathrm{n}}$ bias-corrected MOD-ET shows moderate overestimations of ET (EF) when applied over water-stressed regions (Fig. 4), which is similar to observations by Kim and Hogue $^{6}$ and Tang et al. ${ }^{31}$ Despite improved bias when comparing originally derived MOD-ET 

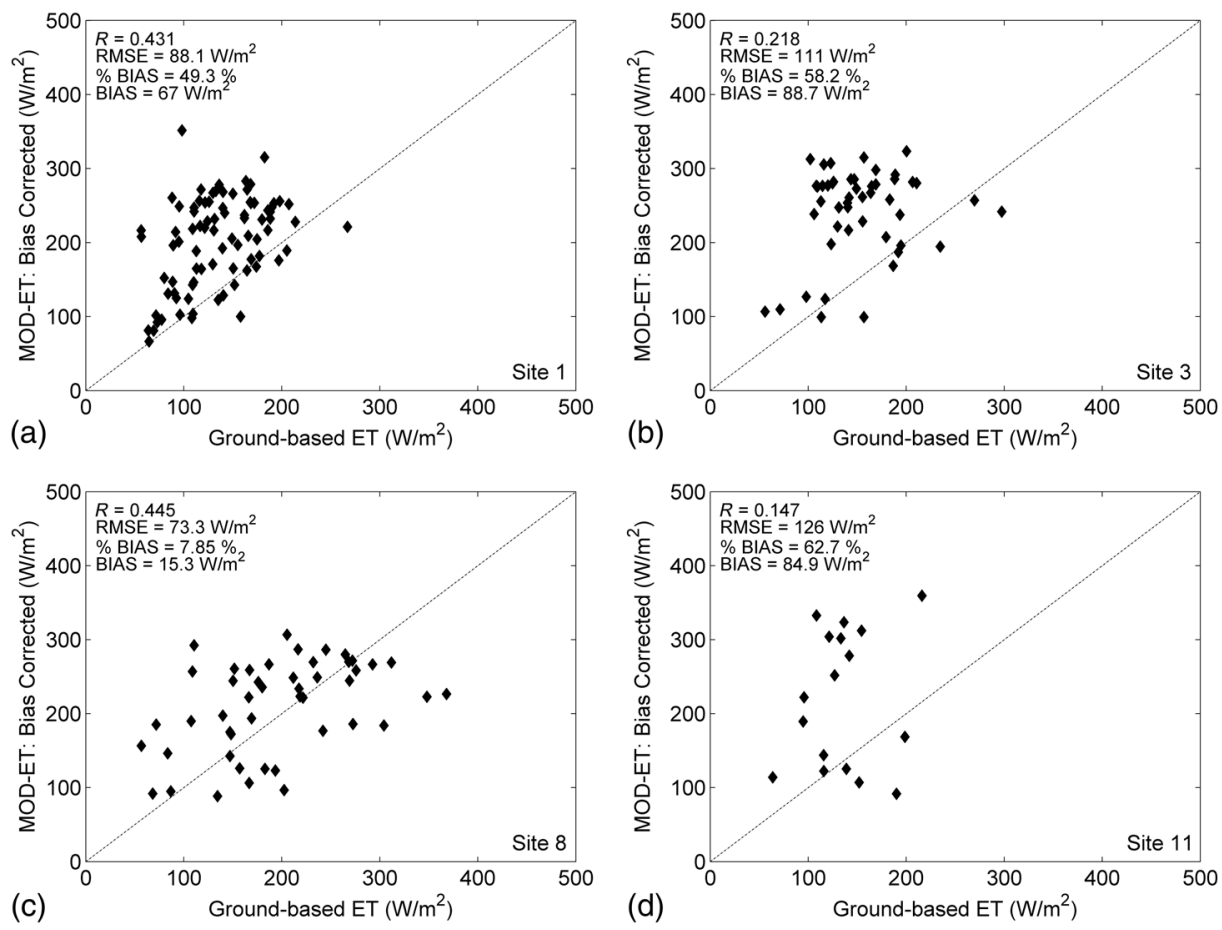

Fig. $4 R_{\mathrm{n}}$ bias-corrected MOD-ET versus ground-based ET at each site. Correlation coefficient $(R)$, RMSE, percent bias, and bias are also presented.

estimates to values reported in Kim and Hogue, ${ }^{6} R_{\mathrm{n}}$ bias-corrected MOD-ET estimates suggest that calculated EF from the $\Delta T_{\mathrm{s}}-$ EVI domain under water-stressed conditions remains an issue.

MOD-ET calculated without topographic correction show minimal variation compared to those reported using the topographic correction. All sites have a percent difference in correlation between $1.4 \%$ and $3.7 \%$, with correlations decreasing for all sites. Sites 1, 3, 8, and 11 report a percent difference in RMSE of 7.2, 8.2, -4.5 , and $4.8 \mathrm{~W} / \mathrm{m}^{2}$, respectively. Changes in bias are also relatively small when omitting topographic correction, with sites 1,3 , and 11 reporting an increase of $8.7 \mathrm{~W} / \mathrm{m}^{2}$ on average, where site 8 reports a decrease of $8.3 \mathrm{~W} / \mathrm{m}^{2}$. Given that slope has a stronger influence on ET than elevation, ${ }^{63}$ minute changes in MOD-ET estimates

Table 3 RMSE and $R$ values for triangle-based ET from recent relevant studies.

\begin{tabular}{lccc}
\hline \hline Study & Site & $R$ (unit less) & RMSE $\left(\mathrm{W} / \mathrm{m}^{2}\right)$ \\
\hline Tang et al. $^{31}$ & Audubon Ranch & 0.47 & 45.4 \\
& Kendall Grassland & 0.68 & 36.8 \\
Wang and Jia ${ }^{62}$ & Average between all 14 sites & 0.57 & 22.0 \\
Kim and Hogue ${ }^{6}$ & Kendall & 0.43 & 33.0 \\
& Charleston & 0.85 & 48.0 \\
& Lewis Spring & 0.86 & 32.0 \\
MOD-ET (bias corrected) & Santa Rita & 0.69 & 45.0 \\
& 1 & 0.43 & 88.1 \\
& 3 & 0.22 & 111.0 \\
\hline \hline
\end{tabular}


from topographic correction are likely associated with the relatively flat surface of the watershed. Despite an elevation range between 1900 and $2600 \mathrm{~m}, 93 \%$ of the watershed has a slope less than $15 \mathrm{deg}$, with sites located on and immediately surrounded by flat terrain (slope $<6 \mathrm{deg}$ ) [Fig. 2(a)].

The average annual ET response to elevation and slope for different aspect angles over the Sagehen basin is also highlighted (Fig. 5). Years 2010 to 2012 show an expected increase in ET with elevation, with peak values occurring between roughly 2050 and $2200 \mathrm{~m}$, before steadily decreasing at elevations greater than $2300 \mathrm{~m}$ [Figs. 5(a), 5(c), 5(e), and 5(g)]. Marginal variability between aspect angles is attributed to the frequency of smaller slopes [Fig. 2(a)], dampening the effects aspect may have on ET estimation. However, we note ET values for the south-facing slopes are lower than those for the north-, east-, and west-facing slopes. This trend is most prominent between 2100 and $2300 \mathrm{~m}$ for years 2011 and 2013 [Figs. 5(c) and 5(g)]. South-facing slopes receive more direct sunlight, heating the surface, and possibly enhancing the turbulent mixing of the near surface air mass. Consequently, the increase in $R_{\mathrm{n}}$ is repartitioned into sensible heat, causing a decrease in the latent heat flux and available moisture for ET, which is similar to Zhao and $\mathrm{Liu}^{63}$ and Gao et al. ${ }^{64}$ Specifically, Zhao and $\mathrm{Liu}^{63}$ reported ET values for south-facing slopes are lower than north-facing slopes, while Gao et al ${ }^{64}$ indicated that ET for south-facing woodland and grassland sites tended to decrease with increasing elevation.

In addition to slope and slope aspect, trends in ET with elevation may also be attributed to the soil moisture and vegetation properties at specific elevations. ${ }^{6,8,19-21,26,65,66}$ Mean summer season EVI with elevation trends closely follow those of ET, with lower EVI values ( 0.47 to 0.50$)$ at the lowest elevations in the basin (1880 to $2000 \mathrm{~m}$ ) (Fig. 6). Peak EVI values ( 0.52 to 0.53 ) occur around $2100 \mathrm{~m}$ (Fig. 6), coinciding with peak ET values (Fig. 5). EVI values then decrease from $\sim 0.50$ to 0.40 from $2100 \mathrm{~m}$ in elevation to $2600 \mathrm{~m}$ (Fig. 6), similar to overall trends in ET (Fig. 5).

Similar to our modeled $R_{\mathrm{n}}$ underestimation, bias between MOD-ET and ground-based ET may be attributed to the discrepancy between spatial scales of the satellite imagery and surface stations. Ground-based measurements are influenced by observation height, ${ }^{8}$ canopy structure,

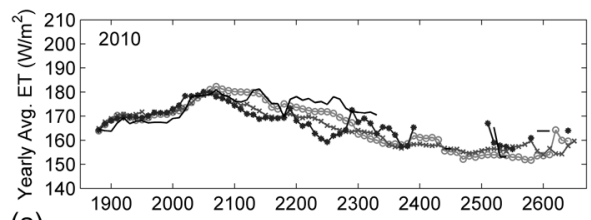

(a)

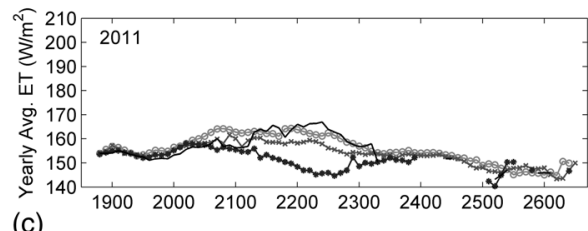

(c)

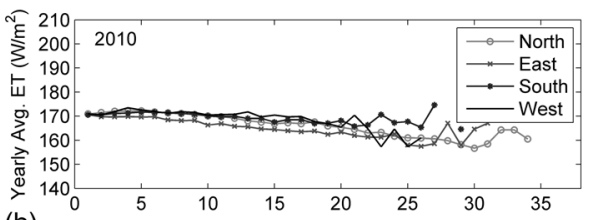

(b)

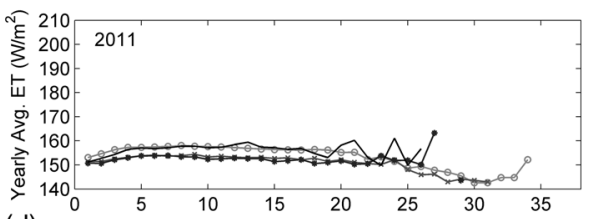

(d)

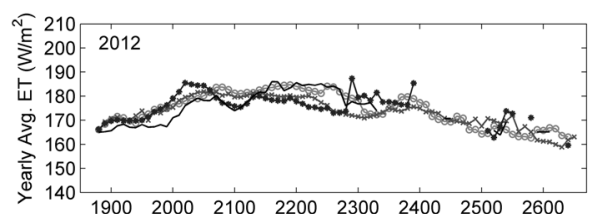

(e)
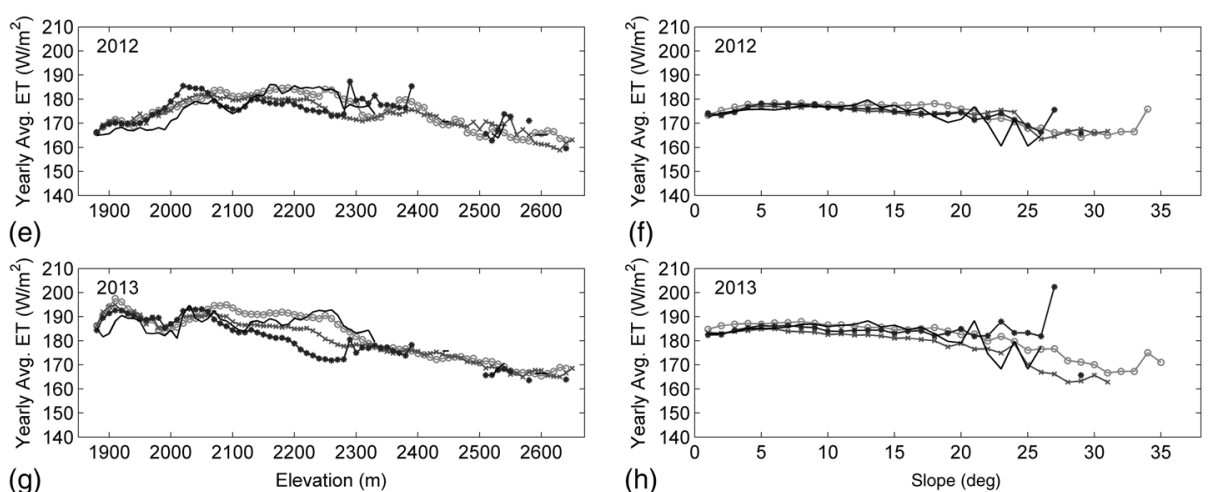

(f)

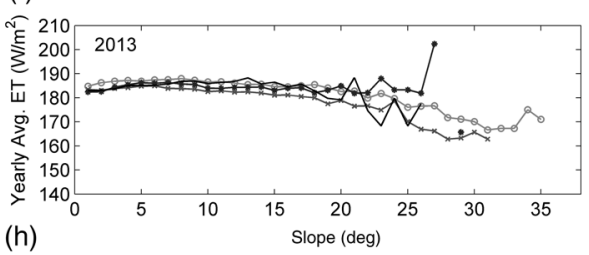

(h)

Fig. 5 The ET as a function of elevation (a, c, e, and g) and slope (b, d, f, and h) for the cardinal aspect within the Sagehen basin. 


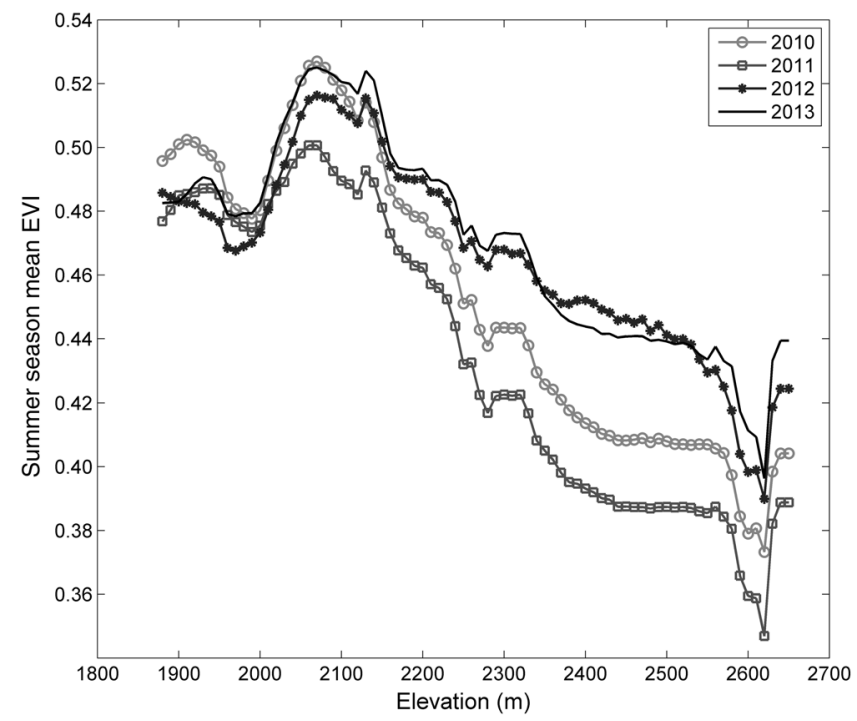

Fig. 6 Summer season mean EVI response to elevation for years 2010 to 2013 over the Sagehen basin.

and other local environmental factors. ${ }^{66,67}$ Therefore, it is a changing variable on both space and time scales, while a satellite measurement with fixed pixel size is characterized as a static constant (incapable of deciphering small-scale heterogeneity). ${ }^{62}$ Additional factors contributing to observed biases include uncertainties from instrumental measurements and remote-sensing retrievals. $^{31}$

\subsubsection{Distributed evapotranspiration comparison}

ET estimates derived during this study are further evaluated through a comparison to global MODIS ET datasets (MOD16A2) ${ }^{56}$ and SSEBop. ${ }^{17}$ Results show considerable underestimation of MOD16 monthly ET across all sites, with bias values between -14.0 and $-84.4 \mathrm{~mm} / \mathrm{month}$ (Table 4 and Fig. 7) when compared to ground-based estimates. SSEBop shows slightly improved bias, with a large range between -3.8 and $-113.0 \mathrm{~mm} / \mathrm{month}$ (Table 4). Focusing on site 1, which has the largest available ground-based ET dataset, we find that MOD-ET overestimates monthly totals during all months (June, July, August, September, and October). SSEBop and MOD16 produce a systematic underestimation of monthly total ET, while matching the overall pattern of observed data (correlations of 0.39 and 0.36 , respectively) (Fig. 7). However, MOD16 monthly total estimates are considerably lower than those reported by SSEBop and MOD-ET, with slightly improved bias at site 8 when compared to SSEBop. Due to the unavailability of ground-based ET datasets at the subsequent sites, we cannot further assess the degree of success of MOD-ET as compared to MOD16 and SSEBop. Despite the lack of available ground-based ET estimates, a clear pattern in the magnitude of estimated monthly

Table 4 RMSE, correlation $(R)$, and bias values of MOD-ET, MOD16, and SSEBop monthly total ET products compared against observed.

\begin{tabular}{|c|c|c|c|c|c|c|c|c|c|}
\hline \multirow[b]{2}{*}{ Site } & \multicolumn{3}{|c|}{ RMSE (mm/month) } & \multicolumn{3}{|c|}{$R$ (unit less) } & \multicolumn{3}{|c|}{ Bias (mm/month) } \\
\hline & MOD-ET & MOD16 & SSEBop & MOD-ET & MOD16 & SSEBop & MOD-ET & MOD16 & SSEBop \\
\hline 1 & 87.5 & 93.0 & 51.6 & 0.58 & 0.36 & 0.39 & 73.1 & -84.4 & -27.6 \\
\hline 3 & 158.0 & 81.2 & 64.9 & 0.22 & 0.45 & 0.25 & 136.0 & -55.8 & -3.8 \\
\hline 8 & 42.8 & 152.0 & 127.0 & 0.75 & 0.79 & 0.43 & 2.7 & -144.0 & -113.0 \\
\hline 11 & 199 & 60.6 & 69.8 & -0.12 & -0.50 & -0.29 & 175.0 & -13.9 & -21.4 \\
\hline
\end{tabular}



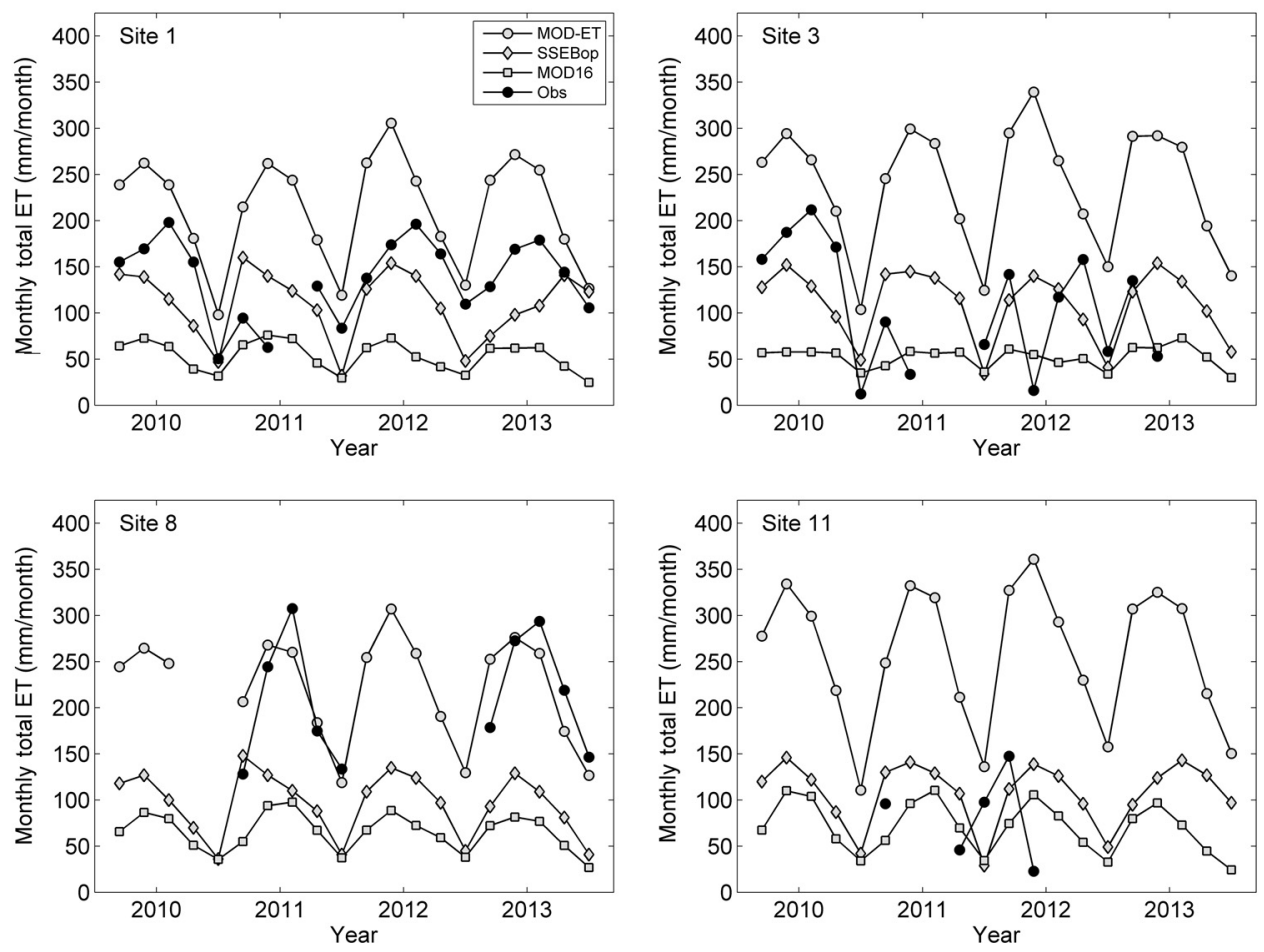

Fig. 7 Monthly total ET estimate comparisons between SSEBop, MOD16, and the developed MOD-ET against ground-based ET.

total ET is presented, with MOD-ET producing the largest monthly total ET estimates, followed in magnitude by SSEBop and MOD16.

Focusing on site 1 (as done previously), we find SSEBop and MOD-ET estimates display a substantial improvement in overall performance compared to MOD16 estimates. The poor performance of MOD16 can be attributed to both elevation and climate. ${ }^{60}$ Velpuri et al. ${ }^{60}$ report a decrease in MOD16 ET accuracy with increasing elevation, as well as a negative bias in more arid, steppe, and cold region climates. Velpuri et al. ${ }^{60}$ also demonstrate that SSEBop does not decrease in accuracy with increasing elevation, which is attributed to the enhanced algorithm by Senay et al. ${ }^{17}$ Velpuri et al. ${ }^{60}$ also note better agreement in SSEBop over climate zones covering most of the western United States. Trends seen in Velpuri et al. ${ }^{60}$ are similar to those observed in our MOD-ET, with similar topography, vegetation, and relative climate at the high elevation sites making for a reasonable comparison.

\section{Summary and Conclusions}

The current work investigates the robustness of a stand-alone MODIS-based ET product for all sky conditions, with a focus on a subalpine basin. The evaluated method provides a simple and direct estimate of ET, without the need for ground-based meteorological data and shows the potential for monitoring ET in regions where little to no gauged data exists. The approach is tested at four sites (sites 1, 3, 8, and 11) within the Sagehen Creek watershed in the northern Sierra Nevada.

The $R_{\mathrm{n}}$ model used in this study systematically underestimates net radiation at all sites, with bias values ranging from -83 to $-110 \mathrm{~W} / \mathrm{m}^{2}$. Similar trends are reported by Kim and Hogue ${ }^{6}$ and may be the result of a shortwave radiation scheme used in the current algorithm.

Originally derived MOD-ET 8-day estimates show relatively strong correlation and minimal bias at all sites when compared to ground-based measurements. Improved bias under increased water stress is likely attributed to a nonlinear decomposition ${ }^{56}$ allowing for a better representation of available soil moisture. Net radiation bias-corrected 8-day ET estimates are slightly overestimated at all sites with bias values between 15 and $89 \mathrm{~W} / \mathrm{m}^{2}$. Despite improved bias 
when comparing originally derived MOD-ET estimates, the $R_{\mathrm{n}}$ bias-corrected MOD-ET estimates suggest that estimating EF from the $\Delta T_{\mathrm{s}}-\mathrm{EVI}$ domain under water-stressed conditions remains an unresolved issue. This is attributed to the influence of the deeper root zone soil moisture on total ET in regions experiencing increased water stress. Although improved through a nonlinear decomposition, including a certain degree of water stress, the triangular relationship between LST and EVI still may not be able to correctly represent this deeper soil moisture available to plants.

Comparisons between topographically corrected MOD-ET and nontopographically corrected MOD-ET led to small variations in ET estimates. Reported changes in RMSE and bias from topographically corrected to nontopographically corrected ET estimates are 2.5 and $4.5 \mathrm{~W} / \mathrm{m}^{2}$, respectively, on average between the sites. Minor differences are associated with the relatively flat surface of the area directly surrounding all four sites (slope $<6 \mathrm{deg}$ ).

Additional uncertainty may result from the obvious scale differences between the MODISbased value and the ground-based station. Heterogeneity within the MODIS pixel contributes to the error in ET due to the scale differences between the satellite and surface point measurement.

MOD16 ET significantly underestimates monthly totals, with bias values ranging from -13.9 to $-144.0 \mathrm{~W} / \mathrm{m}^{2}$. Underestimation by MOD16 is likely attributed to the models decreasing accuracy in ET approximation with increasing elevation and reported negative bias in arid, steppe, and cold arid regions. ${ }^{53}$ However, comparisons made between the MOD-ET product and the SSEBop ET product with observed monthly total ET estimates show slightly improved results, with correlations between 0.58 and 0.39 for site 1 , respectively.

Overall, the proposed MOD-ET model performs relatively well and results correspond with past studies and the current SSEBop model. Independence from ancillary data and near real-time applicability makes the MOD-ET suitable for monitoring ET in regions where little or no gauged data exists. We note that there are still significant challenges present in the estimation of actual ET in water-stressed type environments with complex topography and vegetative/soil moisture heterogeneity. However, the products utilized in the MOD-ET algorithm have the ability to reflect spatial and temporal dynamics from climate and land surface alteration. For example, the Sagehen Creek Experimental Forest is currently undergoing extensive forest thinning activities to reduce natural vegetation build-up and restore a healthy wildfire regime. Such activities will alter the land cover and ET dynamics. The ability to incorporate this MOD-ET product may enhance future hydrologic studies in this and other forested regions undergoing acute land use change.

\section{Appendix: Derivation of Ground-Based Net Radiation and ET}

Ground-based net radiation is estimated according to

$$
R_{\mathrm{n}}=R_{\mathrm{s}}\left(1-A_{0}\right)+\varepsilon_{\mathrm{s}} \mathrm{R} 1 \downarrow-\mathrm{R} 1 \uparrow,
$$

where $R_{\mathrm{s}}$ is the shortwave radiation (provided at the site) $\left(\mathrm{W} / \mathrm{m}^{2}\right), A_{0}$ is the albedo of the surface (unitless), $\varepsilon_{\mathrm{s}}$ is the surface emissivity (unitless), and $\mathrm{Rl} \downarrow$ and $\mathrm{Rl} \uparrow$ are downward and upward longwave radiation $\left(\mathrm{W} / \mathrm{m}^{2}\right)$, respectively. $A_{0}$ and $\varepsilon_{\mathrm{s}}$ are approximated as 0.25 and 0.97 , respectively, after considering the vegetative properties at each site and comparing to corresponding natural surfaces as reported by Brutsaert. ${ }^{37} \mathrm{Rl} \uparrow$ is estimated according to the Stefan-Boltzmann equation as

$$
\mathrm{Rl} \uparrow_{\text {clear }}=\varepsilon_{\mathrm{s}} \sigma T_{\mathrm{s}}^{4}
$$

where $\sigma$ is the Stephan-Boltzmann constant $\left(5.67 \times 10^{-8} \mathrm{~W} \mathrm{~m}^{-2} \mathrm{~K}^{-4}\right)$, and $T_{\mathrm{s}}$ is the LST $(\mathrm{K})$. $\mathrm{R} 1 \downarrow$ for all sky conditions is approximated by first calculating R1 $\downarrow$ under clear sky conditions [Eq. (20)]

$$
\mathrm{R} 1 \downarrow_{\text {clear }}=\varepsilon_{\mathrm{ac}} \sigma T_{\mathrm{a}}^{4},
$$

where $\varepsilon_{\mathrm{ac}}$ is defined as the atmospheric emissivity under clear skies and can be written as 


$$
\varepsilon_{\mathrm{ac}}=a\left(\frac{e_{\mathrm{a}}}{T_{\mathrm{a}}}\right)^{\mathrm{b}}
$$

where $e_{\mathrm{a}}$ is the vapor pressure of air (hPa), and $a$ and $b$ are constants derived to be 1.24 and $1 / 7$ under average conditions that represent a standard atmosphere. ${ }^{68-70} \mathrm{Rl} \downarrow$ for all sky conditions is then estimated by

$$
\mathrm{Rl} \downarrow=\mathrm{R} 1 \downarrow_{\text {clear }}\left(1+a_{1} f_{\mathrm{c}}^{\mathrm{b} 1}\right)
$$

where $f_{\mathrm{c}}$ is the fractional cloudiness and $a_{1}$ and $b_{1}$ are 0.0496 and 2.45 , respectively, derived from Sugita and Brutsaert. ${ }^{71}$

The standardized FAO Penman-Monteith ET equation is intended to simplify and clarify the presentation and application of the method and is expressed as

$$
\mathrm{ET}_{0}=\frac{0.408 \Delta\left(R_{\mathrm{n}}-G\right)+\gamma \frac{C_{\mathrm{n}}}{T+273} u_{2}\left(e_{\mathrm{s}}-e_{\mathrm{a}}\right)}{\Delta+\gamma\left(1+C_{\mathrm{d}} u_{2}\right)},
$$

where $\mathrm{ET}_{0}$ is the reference $\mathrm{ET}\left(\mathrm{mm} \mathrm{d}^{-1}\right), R_{\mathrm{n}}$ is the calculated net radiation at the crop surface $\left(\mathrm{MJ} \mathrm{m}^{-2} \mathrm{~d}^{-1}\right), G$ is the soil heat flux density at the soil surface $\left(\mathrm{MJ} \mathrm{m}^{-2} \mathrm{~d}^{-1}\right), T$ is the mean daily or hourly air temperature $\left({ }^{\circ} \mathrm{C}\right), u_{2}$ is the mean daily wind speed at $2 \mathrm{~m}$ height $\left(\mathrm{ms}^{-1}\right), e_{\mathrm{s}}$ is the saturation vapor pressure $(\mathrm{kPa}), e_{\mathrm{a}}$ is the mean actual vapor pressure $(\mathrm{kPa}), \Delta$ is the slope of the saturation vapor pressure-temperature curve $\left(\mathrm{kPa}^{\circ} \mathrm{C}^{-1}\right), \gamma$ is the psychrometric constant $\left(\mathrm{kPa}^{\circ} \mathrm{C}^{-1}\right), C_{\mathrm{n}}$ is the numerator constant that changes with reference type and calculation time step $\left(\mathrm{K} \mathrm{mm} \mathrm{s}^{3} \mathrm{Mg}^{-1} \mathrm{~d}^{-1}\right)$, and $C_{\mathrm{d}}$ is the denominator constant that changes with reference type and calculation time step $\left(\mathrm{s} \mathrm{m}^{-1}\right)$. The 0.408 coefficient has units of $\mathrm{m}^{2} \mathrm{~mm} \mathrm{MJ}^{-1}$. The reference surface used in the estimation of ET is expressed as a short crop (similar to clipped grass).

Actual ET, denoted by $\mathrm{ET}_{\mathrm{act}}$, is calculated as

$$
\mathrm{ET}_{\mathrm{act}}=K_{\mathrm{s}} K_{\mathrm{c}} \mathrm{ET}_{0}
$$

where $K_{\mathrm{s}}$ is the soil stress coefficient (0 to 1.0), $K_{\mathrm{c}}$ is the crop coefficient (determined to be 1.0), ${ }^{38}$ and $\mathrm{ET}_{0}$ is the reference ET reported at each site. $K_{\mathrm{s}}$ is given by

$$
K_{\mathrm{s}}=\frac{\mathrm{TAW}-D_{\mathrm{r}}}{\mathrm{TAW}-\mathrm{RAW}}
$$

where TAW is the total available soil water in the root zone $(\mathrm{mm})$, RAW is the readily available soil water in the root zone $(\mathrm{mm})$, and $D_{\mathrm{r}}$ is root zone depletion $(\mathrm{mm})$. The total available water is estimated as the difference between water content at field capacity and wilting point, ${ }^{38}$ and is expressed as

$$
\mathrm{TAW}=1000\left(\theta_{\mathrm{fc}}-\theta_{\mathrm{wp}}\right) z_{\mathrm{r}}
$$

where $z_{\mathrm{r}}$ is the maximum rooting depth $(\mathrm{m})$. Readily available water of the root zone is estimated as

$$
\mathrm{RAW}=p(\mathrm{TAW})
$$

where $p$ is the fraction of TAW that a crop can extract from the root zone without experiencing stress. ${ }^{38}$ Following FAO-56 procedures, $p$ is estimated as 0.49 , while $z_{\mathrm{r}}, \theta_{\mathrm{fc}}$, and $\theta_{\mathrm{wp}}$ are determined to be $2.0 \mathrm{~m},{ }^{72-74} 0.33,{ }^{75}$ and $0.13,{ }^{75}$ respectively. Following the calculations of TAW and RAW, root zone depletion is estimated as

$$
D_{\mathrm{r}}=1000\left(\theta_{\mathrm{fc}}-\theta_{i}\right) z_{\mathrm{r}}
$$

where $\theta_{i}$ is the average soil water content in the active rooting depth for a given day. Daily average soil water content estimates at each site (depth of 40 to $100 \mathrm{~cm}$ ) are acquired through the national land data assimilation model (NOAH) output. If the root zone depletion for a given 
day is less than or equal to RAW, $K_{\mathrm{s}}$ is equal to 1.0 and no stress is induced on the plant. When root zone depletion is greater than RAW, $K_{\mathrm{S}}$ varies from 0 to 1 and is used to scale reported reference ET to actual ET under water-stressed conditions. Additional information pertaining to the FAO-56 procedure can be found in Allen et al. ${ }^{38}$

\section{Acknowledgments}

Financial support for this work was partially supported by the Poate Graduate Fellowship from the Colorado School of Mines, an NSF Water Sustainability and Climate Grant (EAR12040235), NASA Grant NNX15AB28G, and funding from The Nature Conservancy. The authors also thank two anonymous reviewers, whose thorough and insightful comments have strengthened the article.

\section{References}

1. S. B. Idso et al., "The utility of surface temperature measurements for the remote sensing of surface soil water status," J. Geophys. Res. 80, 3044-3049 (1975).

2. Z. Su, "The surface energy balance system (SEBS) for estimation of turbulent heat fluxes," Hydrol. Earth Syst. Sci. 6(1), 85-99 (2002).

3. Z. L. Li et al., "A review of current methodologies for regional evapotranspiration estimation from remotely sensed data," Sensors 9, 3801-3853 (2009).

4. R. Tang, Z. Li, and B. Tang, "An application of the $T_{s}-$ VI triangle method with enhanced edges determination for evapotranspiration estimation from MODIS data in arid and semiarid regions: implementation and validation," Remote Sens. Environ. 114(3), 540-551 (2010).

5. C. Y. Xu and V. P. Singh, "Evaluation of three complementary relationship evapotranspiration models by water balance approach to estimate actual regional evapotranspiration in different climate regions," J. Hydrol. 308(1-4), 105-121 (2005).

6. J. Y. Kim and T. S. Hogue, "Evaluation of a MODIS triangle-based evapotranspiration algorithm for semi-arid regions," J. Appl. Remote Sens. 7(1), 073493 (2013).

7. Th. Foken and B. Wichura, "Tools for quality assessment of surface-based flux measurements," Agric. For. Meteorol. 78(1-2), 83-105 (1996).

8. H. P. Schmid and C. R. Lloyd, "Spatial representativeness and the location bias of flux footprints over inhomogeneous areas," Agric. For. Meteorol. 93(3), 195-209 (1999).

9. B. Chen et al., "Comparison of regional carbon flux estimates from $\mathrm{CO}_{2}$ concentration measurements and remote sensing based footprint integration," Global Biogeochem. Cycles 22(2), 1-15 (2008).

10. K. Mallick et al., "Latent heat flux estimation in clear sky days over Indian agroecosystems using noontime satellite remote sensing data," Agric. For. Meteorol. 149(10), 1646-1665 (2009).

11. J. D. Kalma and D. L. B. Jupp, "Estimating evapotranspiration from pasture using infrared thermometry: evaluation of a one-layer resistance model," Agric. For. Meteorol. 51, 223 246 (1990).

12. K. Nishida et al., An operational remote sensing algorithm of land surface evaporation," J. Geophys. Res. 108, 1-14 (2003).

13. R. Allen et al., "Satellite-based energy balance for mapping evapotranspiration with internalized calibration (METRIC)—applications," J. Irrig. Drain. E 133(4), 395-406 (2007).

14. W. G. M. Bastiaanssen et al., "A remote sensing surface energy balance algorithm for land (SEBAL) 1. Formulation," J. Hydrol. 212-213, 198-212 (1998).

15. W. G. M. Bastiaanssen, "SEBAL-based sensible and latent heat fluxes in the irrigated Gediz Basin, Turkey," J. Hydrol. 229(1-2), 87-100 (2000).

16. G. B. Senay et al., "A coupled remote sensing and simplified surface energy balance approach to estimate actual evapotranspiration from irrigated fields," Sensors 7(6), 9791000 (2007). 
17. G. B. Senay et al., "Operational evapotranspiration mapping using remote sensing and weather datasets: a new parameterization for the SSEB approach," J. Am. Water Resour. Assoc. 49(3), 577-591 (2013).

18. T. N. Carlson, R. R. Gillies, and E. M. Perry, "A method to make use of thermal infrared temperature and NDVI measurements to infer surface soil water content and fractional vegetation cover," Remote Sens. Rev. 9(1-2), 161-173 (1994).

19. L. Jiang and S. Islam, "A methodology for estimation of surface evapotranspiration over large areas using remote sensing observations," Geophys. Res. Lett. 26(17), 2773-2776 (1999).

20. L. Jiang and S. Islam, "Estimation of surface evapotranspiration map over Southern Great Plains using remote sensing data," Water Resour. Res. 37(2), 329-340 (2001).

21. L. Jiang and S. Islam, "An intercomparison of regional latent heat flux estimation using remote sensing data," Int. J. Remote Sens. 24(11), 2221-2236 (2003).

22. K. Wang, Z Li, and M. Cribb, "Estimation of evaporative fraction from a combination of day and night land surface temperature and NDVI: a new method to determine the PriestleyTaylor parameter," Remote Sens. Environ. 102(3-4), 293-305 (2006).

23. J. C. Price, "Using spatial context in satellite data to infer regional scale evapotranspiration," IEEE Geosci. Remote Sens. 28(5), 940-948 (1990).

24. M. S. Moran et al., "Estimating crop water deficit using the relation between surface-air temperature and spectral vegetation index," Remote Sens. Environ. 49(3), 246-263 (1994).

25. S. N. Goward, "Observed relation between thermal emission and reflected spectral radiance of a complex vegetated landscape," Remote Sens. Environ. 18(2), 137-146 (1985).

26. T. N. Carlson, R. R. Gillies, and T. J. Schmugge, "An interpretation of methodologies for indirect measurement of soil water content," Agric. For. Meteorol. 77(3-4), 191-205 (1995).

27. Q. K. Hassan et al., "A wetness index using terrain-corrected surface temperature and normalized difference vegetation index derived from standard MODIS products: an evaluation of its use in a humid forest-dominated region of eastern Canada," Sensors 7(10), 2028-2048 (2007).

28. E. F. Lambin and D. Ehrlich, "The surface temperature-vegetation index space for land cover and land-cover change analysis," Int. J. Remote Sens. 17(3), 463-487 (1996).

29. R. Nemani et al., "Developing satellite-derived estimates of surface moisture status," J. Appl. Meteorol. 32, 548-557 (1993).

30. J. Tian et al., "Impact of the spatial domain size of the performance of the $T_{\mathrm{s}}-\mathrm{VI}$ triangle method in terrestrial evapotranspiration estimation," Remote Sens. 5(4), 1998-2013 (2013).

31. R. Tang, Z.-L. Li, and K.-S. Chen, "Validating MODIS-derived land surface evapotranspiration with in situ measurements at two AmeriFlux sites in a semiarid region," J. Geophys. Res. 116, 1-14 (2011).

32. P. M. Teillet, B. Guindon, and D. G. Goodenough, "On the slope-aspect correction of multispectral scanner data," Can. J. Remote Sens. 8(2), 84-106 (1982).

33. Y. Liu and T. Hiyama, "A scaling approach for satellite-derived land surface temperature over terrain area," Remote Sens. Environ. 105, 115-128 (2005).

34. S. Stisen et al., "Combining the triangle method with thermal inertia to estimate regional evapotranspiration-applied to MSG-SEVIRI data in the Senegal River basin," Remote Sens. Environ. 112(3), 1242-1255 (2008).

35. Western Regional Climate Center, "Period of record monthly climate summary," http:// www.wrcc.dri.edu/cgi-bin/cliMAIN.pl?ca9043 (June 2015).

36. S. Jin et al., "A comprehensive change detection method for updating the National Land Cover Database to circa 2011," Remote Sens. Environ. 132, 159-175 (2013).

37. W. Brutsaert, "Water aloft: fluid mechanics of the lower atmosphere," Chapter 2 in Hydrology: An Introduction, pp. 57-66, Cambridge University Press, Cambridge (2005).

38. R. G. Allen et al., "Crop Evapotranspiration: Guidelines for Computing Crop Water Requirements," Food and Agriculture Organization of the United Nations, Rome (1998).

39. A. A. Gitelson, Y. J. Kaufman, and M. N. Merzlyak, "Use of a green channel in remote sensing of global vegetation from EOS-MODIS," Remote Sens. Environ. 58(3), 289-298 (1996). 
Knipper, Kinoshita, and Hogue: Evaluation of a moderate resolution imaging spectroradiometer...

40. A. R. Huete et al., "Global-scale analysis of vegetation indices for moderate resolution monitoring of terrestrial vegetation," Proc. SPIE 3868, 141-151 (1999).

41. L. Ji et al., "Agreement evaluation of AVHRR and MODIS 16-day composite NDVI data sets," Int. J. Remote Sens. 29(16), 4839-4861 (2008).

42. C. O. Justice et al., "An overview of MODIS land data processing and product status," Remote Sens. Environ. 83(1-2), 3-15 (2002).

43. Earth Observing System Data and Information System (EOSDIS). Earth Observing System Clearing House (ECHO) / Reverb, "Version 10.111.0," EOSDIS, Goddard Space Flight Center (GSFC) National Aeronautics and Space Administration (NASA), Greenbelt, Maryland, http://reverb.earthdata.nasa.gov (2009).

44. J. Y. Kim and T. S. Hogue, "Evaluation of a MODIS-based potential evapotranspiration product at the point scale," J. Hydrometeorol. 9, 444-460 (2008).

45. M. Paulescu and Z. Schlett, "Performance assessment of global solar irradiation models under Romanian climate," Renewable Energy 29(5), 767-777 (2004).

46. G. Bisht and R. L. Bras, "Estimation of net radiation from the MODIS data under all sky conditions: Southern Great Plains case study," Remote Sens. Environ. 114(7), 1522-1534 (2010).

47. W. Brutsaert, "On a derivable formula for long-wave radiation from clear skies," Water Resour. Res. 11(5), 742-744 (1975).

48. J. W. Zillman, A Study of Some Aspects of the Radiation and Heat Budgets of the Southern Hemisphere Oceans, Australian Government Public Service, Canberra (1972).

49. S. Niemelä, P. Räisänen, and H. Savijärvi, "Comparison of surface radiative flux parameterizations: part II. Shortwave radiation," Atmos. Res. 58(2), 141-154 (2001).

50. G. Bisht et al., "Estimation of the net radiation using MODIS (moderate resolution imaging spectroradiometer) data for clear sky days," Remote Sens. Environ. 97(1), 52-67 (2005).

51. A. Slingo, "A GCM parameterization for the shortwave radiative properties of water clouds," J. Atmos. Sci. 46, 1419-1427 (1989).

52. W. Liu et al., "Estimation of the land surface instantaneous net radiation and its diurnal cycle integrating multi-source remote sensing data under clear sky," in IEEE Int. Geoscience and Remote Sensing Symp. (IGARSS), pp. 2109-2112 (2011).

53. Z. Wan et al., "Validation of the land-surface temperature products retrieved from data," Remote Sens. Environ. 83(1-2), 163-180 (2002).

54. L. Jiang, S. Islam, and T. Carlson, "Towards the uncertainty of surface fluxes estimation and implications for using a simplified approach with remote sensing data," Can. J. Remote Sens. 30(5), 769-787 (2004).

55. R. Allen et al., "Satellite-based ET estimation in agriculture using SEBAL and METRIC," Hydrol. Process. 25, 4011-4027 (2011).

56. Q. Mu, M. Zhao, and S. W. Running, "Improvements to a MODIS global terrestrial evapotranspiration algorithm," Remote Sens. Environ. 115, 1781-1800 (2011).

57. S. W. Running, "Numerical Terradynamic Simulation Group (NTSG)," 2013, School of Forestry, University of Montana, Missoula, Montana ftp://ftp.ntsg.umt.edu/pub/MODIS/ Mirror/MOD16 (10 June 2015).

58. Q. Mu et al., "Development of a global evapotranspiration algorithm based on MODIS and global meteorology data," Remote Sens. Environ. 111, 519-536 (2007).

59. J. L. Monteith, "Evaporation and environment," Symp. Soc. Exp. Biol. 19, 205-234 (1965).

60. N. M. Velpuri et al., "A comprehensive evaluation of two MODIS evapotranspiration products over the conterminous Unite States: using point and gridded FLUXNET and water balance ET," Remote Sens. Environ. 139, 35-49 (2013).

61. D. L. Blodgett, “The U.S. Geological Survey Climate Geo Data Portal: an integrated broker for climate and geospatial data,’ U.S. Geological Survey Fact Sheet, 2013-3019, 2, http:// cida.usgs.gov/gpd (2013).

62. H. Wang and G. Jia, "Regional estimates of evapotranspiration over Northern China using a remote-sensing-based triangle interpolation method," Adv. Atmos. Sci. 30(5), 1479-1490 (2013). 
63. X. Zhao and Y. Liu, "Relative contribution of the topographic influence on the triangle approach for evapotranspiration estimation over mountainous area," Adv. Meteorol. 2014, 1-16 (2014).

64. Y. Gao, D. Long, and Z.-L. Li, "Estimation of daily actual evapotranspiration from remotely sensed data under complex terrain over the upper Chao river basin in North China," Int. J. Remote Sens. 29(11), 3295-3313 (2008).

65. R. R. Gillies and T. N. Carlson, "Thermal remote sensing of surface soil water content with partial vegetation cover for incorporation into climate models," J. Appl. Meteorol. 34, 745-756 (1995).

66. C. Yi, "Momentum transfer within canopies," J. Appl. Meteorol. Climatol. 47, 262-275 (2008).

67. C. Yi et al., "Climate control of terrestrial carbon exchange across biomes and continents," Environ. Res. Lett. 5, 034007 (2010).

68. J. K. Aase and S. B. Idso, "A comparison of two formula types for calculating long wave radiation from the atmosphere," Water Resour. Res. 14, 623-625 (1978).

69. C. S. Daughtry et al., "Spectral estimates of net radiation and soil heat flux," Remote Sens. Environ. 32, 111-124 (1990).

70. M. Mermier and B. Seguin, "Comment on 'On a derivable formula for long-wave radiation from clear skies' by W. Brutsaert," Water Resour. Res. 12, 1327-1328 (1976).

71. M. Sugita and W. Brutsaert, "Cloud effect in the estimation of instantaneous downward longwave radiation," Water Resour. Res. 29, 599-605 (1993).

72. J. Kirchner et al., Visionary for the University of California, Berkeley, Sagehen Creek Field Station, Sagehen Creek Field Station, University of California, Berkeley (2005).

73. J. Canadell et al., "Maximum rooting depth of vegetation types at the global scale," Oecologia 108(4), 583-595 (1996).

74. J. H. Schenk and R. B. Jackson, "Rooting depths, lateral root spreads and below-ground/ above-ground allometries of plants in water-limited ecosystems," J. Ecol. 90, 480-494 (2002).

75. B. J. Cosby et al., "A statistical exploration of the relationships of soil moisture characteristics to the physical properties of soil," Water Resour. Res. 20, 682-690 (1984).

Kyle R. Knipper is a PhD student at the Colorado School of Mines. He received his BS degree in meteorology from Iowa State University and his MS degree in hydrologic science and engineering from the Colorado School of Mines in 2013 and 2015, respectively. His current research specializes in the development and application of remotely sensed products within coupled hydrologic-atmospheric modeling systems to better understand land-atmospheric interactions, with a focus in dynamic environments undergoing acute or chronic disturbances.

Alicia M. Kinoshita is an assistant professor in Civil, Construction, and Environmental Engineering at San Diego State University. She received her MS and PhD degrees in Civil Engineering from the University of California, Los Angeles (UCLA). Her research focuses on disturbed hydrologic processes to improve watershed management practices. She incorporates field data, remote sensing products, and modeling tools to evaluate hydrologic recovery at high temporal and spatial resolutions across large or ungauged areas.

Terri S. Hogue is a Professor in the Department of Civil an Environmental Engineering at the Colorado School of Mines. She received her PhD from the Department of Hydrology and Water Resources at the University of Arizona. Her research focuses on understanding hydrologic and land surface processes, with an emphasis on human interactions with water cycling and resource management. Projects include wildfire impacts, urbanization and ecosystem dynamics, and hydrologic response to climate change. 